Journal of Computer Science 6 (7): 813-816, 2010

ISSN 1549-3636

(C) 2010 Science Publications

\title{
Approximation of Experimental Curve of Nonlinear Deformation of Duralumin
}

\author{
Moh'd Ishaq Abu Halawa \\ Department of Computer Science, Omar Al Mukhtar University, El-Beida BOX 919, Libya
}

\begin{abstract}
Problem statement: The experimental curves for physically nonlinear deformation of aluminum alloy D-16T have been approximated in a temperature field. Approach: An analytical approximation variant of plasticity and physical nonlinearity functions was presented and a numerical processing technique of experimental data was described. Results: The corresponding analytical formulas of plasticity functions and nonlinear creep were proposed with mathematically substantiated parameters. Conclusion: The theoretical and experimental results obtained were compared.
\end{abstract}

Key words: Approximation, plasticity functions, nonlinear creep, relaxation kernel

\section{INTRODUCTION}

To solve the boundary problems of mechanics of a rigid body numerically, it is desirable to employ the mechanical or close to them characteristics of real materials. For this purpose, necessary parameters for aluminum alloy D-16T (duralumin), have been obtained using known experimental data given below. Besides, an analytical approximation variant of plasticity and physical nonlinearity functions is presented and a numerical processing technique of experimental data is described.

\section{MATERIALS AND METHODS}

Approximation of experimental results: Duralumin displays both plastic and viscous properties when subjected to deformation in the temperature field. The physical equations of state correspond to a thermovisco-elasto-plastic material and are accepted in the form:

$$
\begin{aligned}
& \mathrm{s}_{\mathrm{ij}}=2 \mathrm{G}(\mathrm{T})\left(\mathrm{f}_{1}\left(\varepsilon_{\mathrm{u}}, \mathrm{T}\right) \ni_{\mathrm{ij}}-\int_{0}^{\mathrm{t}} \mathrm{R}(\mathrm{t}-\tau) \mathrm{f}_{2}\left(\varepsilon_{\mathrm{u}}, \mathrm{T}\right) \ni_{\mathrm{ij}}(\tau) \mathrm{d} \tau\right), \\
& \sigma=3 \mathrm{~K}(\mathrm{~T})(\varepsilon-\alpha \mathrm{T})
\end{aligned}
$$

Here:

$\mathrm{s}_{\mathrm{ij}}, \ni_{\mathrm{ij}}, \sigma, \varepsilon=$ The deviator and spherical parts of stress $\sigma_{\mathrm{ij}}$ and strain $\varepsilon_{\mathrm{ij}}$ tensors

$\mathrm{f}_{1}\left(\varepsilon_{\mathrm{u}}, \mathrm{T}\right)=1-\omega_{1}\left(\varepsilon_{\mathrm{u}}, \mathrm{T}\right)$, Ilyushin (1948) plasticity function

$\varepsilon_{\mathrm{u}} \quad=$ Strain rate

$\mathrm{f}_{2}\left(\varepsilon_{\mathrm{u}}, \mathrm{T}\right)=$ Universal function of nonlinear creep

$\mathrm{R}(\mathrm{t}) \quad=$ Relaxation kernel

$\alpha=$ Averaged factor of linear temperature expansion
$\mathrm{T}=$ Inhomogeneous and non-stationary temperature field counted from some initial temperature $\mathrm{T}_{0}$

$\mathrm{G}(\mathrm{T}), \mathrm{K}(\mathrm{T})=$ Shear and volume strain module

To describe the dependence of elasticity module on temperature we use the known Bell (1973) formula suggested by him as a result of processing experimental data for over five hundred pure metals and alloys:

$$
\begin{aligned}
& \{\mathrm{G}(\mathrm{T}), \mathrm{K}(\mathrm{T}), \mathrm{E}(\mathrm{T})\}=\{\mathrm{G}(0), \mathrm{K}(0), \mathrm{E}(0)\} \phi(\mathrm{T}), \\
& \varphi(\mathrm{T})=\left\{\begin{array}{lr}
1, & 0<\mathrm{T} / \mathrm{T}_{\mathrm{m}} \leq 0,06 \\
1,03\left(1-\mathrm{T} /\left(2 \mathrm{~T}_{\mathrm{m}}\right)\right), 0,06<\mathrm{T} / \mathrm{T}_{\mathrm{m}} \leq 0,57
\end{array}\right.
\end{aligned}
$$

Where:

$\mathrm{T}_{\mathrm{m}} \quad=$ Melting point of the material

$\mathrm{G}(0), \mathrm{K}(0), \mathrm{E}(0)=$ Module at so-called zeroth stress

They can be determined experimentally based on known $\mathrm{G}_{0}$ at a certain temperature $\mathrm{T}_{0}$ (e.g., at room temperature $20^{\circ} \mathrm{C}$ ) in the form:

$$
G(0)=\frac{G_{0}}{\varphi\left(T_{0}\right)}
$$

Poisson's ratio is anticipated to be independent of temperature. At higher (homologous) temperatures $\mathrm{T} / \mathrm{T}_{\mathrm{m}}>0.57$ a slight deviation of the material behavior from the linear law (2) is possible.

The analytical variant of plasticity function at some constant temperature $\mathrm{T}_{0}$ is accepted:

$\omega_{1}\left(\varepsilon_{\mathrm{u}}, \mathrm{T}_{0}\right)= \begin{cases}0, & \varepsilon_{\mathrm{u}} \leq \varepsilon_{\mathrm{y} 0} \\ \mathrm{~A}_{1}\left(1-\frac{\varepsilon_{\mathrm{y} 0}}{\varepsilon_{\mathrm{u}}}\right)^{\alpha_{1}}, \varepsilon_{\mathrm{u}} & \geq \varepsilon_{\mathrm{y} 0}\end{cases}$ 
Here:

$\varepsilon_{\mathrm{y} 0}=\varepsilon_{\mathrm{y}}\left(\mathrm{T}_{0}\right)$ is strain rate corresponding to yield point at $\mathrm{T}_{0}, \mathrm{~A}_{1}$

$\alpha_{1}=$ Material constants to be determined from known experimental data

To determine experimental values of the plasticity function we use the experimental data on alternate torsion of a circular in profile rod beyond the elasticity limits under the conditions of room temperature presented in Fig. 1a and derived by Gusenkov and Moskvitin (1973). The dependence of relative strain $\varepsilon$ on torque $\mathrm{M}$ at instant deformation (curve 1-direct loading, 2-back loading) is shown:

$$
\mathrm{M}=\frac{\mathrm{M}_{12}}{\mathrm{M}_{\mathrm{y}}}=\frac{\sigma_{12}}{\sigma_{\mathrm{y}}}, \varepsilon=\frac{\varepsilon_{12}}{\varepsilon_{\mathrm{y}}}, \sigma_{\mathrm{y}}=2 \mathrm{G}_{0} \varepsilon_{\mathrm{y}}
$$

At an instant torsion the integral summand should be equated to zero in relations (1). Out of all stress and strain tensor components only $s_{12}=\sigma_{12}$ and $\ni_{12}=\varepsilon_{12}$ will be nonzero. As a result, the following dependence will be true for the experimental curves considered:

$\sigma_{12}=2 \mathrm{G}_{0} \varepsilon_{12}\left(1-\omega_{1}\right)$

Let us divide the left and right-hand sides of Eq. 5 by $\sigma_{\mathrm{y}}$. Then, using the values introduced in (4), we get:

$$
M=\varepsilon\left(1-\omega_{1}\right), \omega_{1}=1-\frac{M}{\varepsilon}
$$

Based on (6), we find the values of plasticity function in experimental points $\omega_{1 n}$ Fig. $1 \mathrm{~b}$. In these points, the condition of approximation should be met:

$$
\omega_{1 \mathrm{n}}=\mathrm{A}_{1}\left(1-\frac{\varepsilon_{\mathrm{y} 0}}{\varepsilon_{\mathrm{un}}}\right)^{\alpha_{1}}
$$

By dividing similar relations for $\mathrm{n}$ and $\mathrm{k}$ experimental points we obtain:

$$
\frac{\omega_{1 \mathrm{n}}}{\omega_{\mathrm{lk}}}=\frac{\left(1-\frac{\varepsilon_{\mathrm{y} 0}}{\varepsilon_{\mathrm{un}}}\right)^{\alpha_{1}}}{\left(1-\frac{\varepsilon_{\mathrm{y} 0}}{\varepsilon_{\mathrm{uk}}}\right)^{\alpha_{1}}}
$$

Where from:

$$
\alpha_{1}=\ln \frac{\omega_{1 \mathrm{n}}}{\omega_{1 \mathrm{k}}} / \ln \frac{1-\frac{\varepsilon_{\mathrm{y} 0}}{\varepsilon_{\mathrm{un}}}}{1-\frac{\varepsilon_{\mathrm{y} 0}}{\varepsilon_{\mathrm{uk}}}}, \mathrm{A}_{1}=\frac{\omega_{\mathrm{ln}}}{\left(1-\frac{\varepsilon_{\mathrm{y} 0}}{\varepsilon_{\mathrm{un}}}\right)^{\alpha_{1}}}
$$

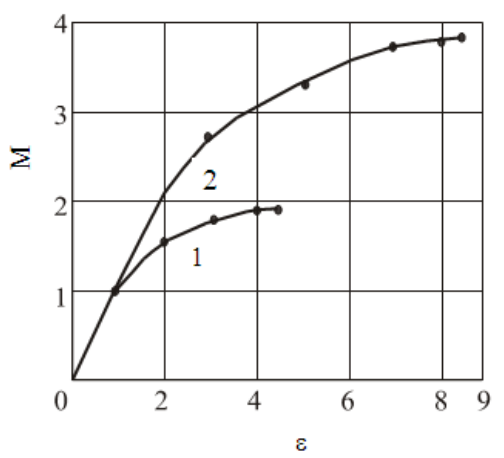

(a)

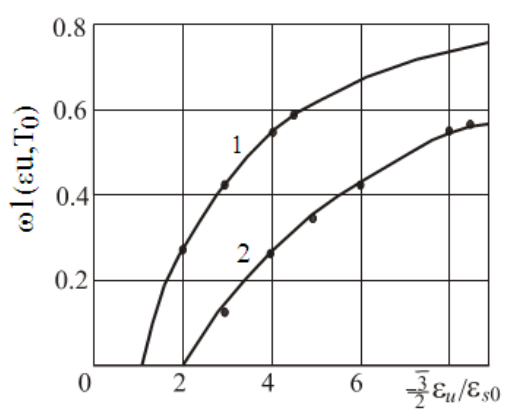

(b)

Fig. 1: Experimental points and theoretical values of plasticity function

After averaging we accept that $\mathrm{A}_{1}=0.96$; $\alpha_{1}=2.34$. We may judge about the approximation accuracy by curves 1 in Fig. 1a and b. Dark points are the experiment; the solid line is calculations.

Plastic properties of metals increase with temperature growth, therefore the diagram for function $\omega_{1}\left(\varepsilon_{\mathrm{u}}, \mathrm{T}\right)$ is supposed to be shifted along the abscissa axis relative to graph $\omega_{1}\left(\varepsilon_{\mathrm{u}}, \mathrm{T}_{0}\right)$ by value $\varepsilon_{\mathrm{y} 0}-\varepsilon_{\mathrm{y}}$ (strain rate $\varepsilon_{\mathrm{y}}$ corresponds to elasticity limit at temperature $\mathrm{T}$ ). Values $\varepsilon_{\mathrm{y}}$ are calculated by the relation of elasticity limit $\sigma_{\mathrm{y}}$ versus temperature (Gorshkov et al., 2002):

$$
\sigma_{y}=\sigma_{y 0} \exp \left\{\kappa\left(\frac{1}{T}-\frac{1}{T_{0}}\right)\right\}, \varepsilon_{y}(T)=\frac{\sigma_{y}(T)}{E(T)}
$$

To determine constants $\kappa$ of the material by (8) we use:

$$
\kappa=\ln \frac{\sigma_{\mathrm{y}}}{\sigma_{\mathrm{y} 0}} /\left(\frac{1}{\mathrm{~T}}-\frac{1}{\mathrm{~T}_{0}}\right)
$$

Its values calculated on the base of Rabotnov (1979) experimental data are given in Table 1. 
Table 1: Approximation parameters of duralumin

\begin{tabular}{|c|c|c|c|}
\hline Parameter & Value & Parameter & Value \\
\hline $\mathrm{E}(0), \mathrm{MPa}$ & $0.8290 \cdot 10^{5}$ & $\alpha_{1}{ }^{*}$ & 2.270 \\
\hline $\mathrm{G}(0), \mathrm{MPa}$ & $0.3075 \cdot 10^{5}$ & $\varepsilon_{\mathrm{y} 0}^{*},(\%)$ & 1.485 \\
\hline $\mathrm{K}(0), \mathrm{MPa}$ & $0.9214 \cdot 10^{5}$ & $\mathrm{~A}_{2}$ & 1.000 \\
\hline $\mathrm{E}_{0}, \mathrm{MPa}$ & $0.7200 \cdot 10^{5}$ & $\alpha_{2}$ & 0.700 \\
\hline $\mathrm{G}_{0}, \mathrm{MPa}$ & $0.2670 \cdot 10^{5}$ & $\varepsilon_{\mathrm{u} 0},(\%)$ & 0.270 \\
\hline $\mathrm{K}_{0}, \mathrm{MPa}$ & $0.8000 \cdot 10^{5}$ & $\mathrm{~A}_{2}{ }^{*}$ & 1.000 \\
\hline$\alpha_{0}, 1 / \mathrm{K}$ & $24.3000 \cdot 10^{-6}$ & $\alpha_{2}{ }^{*}$ & 0.600 \\
\hline $\mathrm{T}_{0}, \mathrm{~K}$ & 293.0000 & $\varepsilon_{\mathrm{u} 0}{ }^{*},(\%)$ & 0.535 \\
\hline $\mathrm{T}_{\mathrm{m},}, \mathrm{K}$ & 933.0000 & $\mathrm{~A}, \mathrm{~s}^{-\alpha}$ & $2.92 \cdot 10^{-4}$ \\
\hline$v$ & 0.3500 & $\beta, \mathrm{s}^{-1}$ & $1.39 \cdot 10^{-7}$ \\
\hline $\mathrm{A}_{1}$ & 0.9600 & $\alpha$ & 0.250 \\
\hline$\alpha_{1}$ & 2.3400 & $\sigma_{\mathrm{y} 0}, \mathrm{MPa}$ & 530.000 \\
\hline$\varepsilon_{\mathrm{y} 0},(\%)$ & 0.7350 & $\rho_{0}, \mathrm{~kg} \mathrm{~m}^{-3}$ & 2700.000 \\
\hline$\sigma_{\mathrm{yo}}, \mathrm{MPa}$ & 340.0000 & $\mathrm{C}_{0}, \mathrm{~J} \mathrm{~kg}^{-1} \cdot \mathrm{K}$ & 880.000 \\
\hline$\kappa, 1 / \mathrm{K}$ & 301.0000 & $\mathrm{k}_{0}, \mathrm{~J} \mathrm{~m}^{-1} \cdot \mathrm{s} \cdot \mathrm{K}$ & 177.000 \\
\hline $\mathrm{A}_{1}^{*}$ & 0.9240 & $\delta$ & 5.600 \\
\hline
\end{tabular}

Thus, by generalizing (3), the plasticity function at a loading by thermal force from the natural state is accepted as:

$\omega_{1}\left(\varepsilon_{\mathrm{u}}, \mathrm{T}\right)= \begin{cases}0, & \varepsilon_{\mathrm{u}} \leq \varepsilon_{\mathrm{y}} \\ \mathrm{A}_{1}\left(1-\frac{\varepsilon_{\mathrm{y} 0}}{\varepsilon_{\mathrm{u}}+\varepsilon_{\mathrm{y} 0}-\varepsilon_{\mathrm{y}}}\right)^{\alpha_{1}}, \varepsilon_{\mathrm{u}}>\varepsilon_{\mathrm{y}}\end{cases}$

The analytical variant of the function of nonlinearity at sign-variable loading $\omega_{1}{ }^{*}\left(\varepsilon_{\mathrm{u}}{ }^{*}, \mathrm{~T}\right)$ is $(9)$ :

$$
\omega_{1}^{*}\left(\varepsilon_{\mathrm{u}}^{*}, \mathrm{~T}\right)= \begin{cases}0, & \varepsilon_{\mathrm{u}}^{*} \leq \varepsilon_{\mathrm{y}}^{*} \\ \mathrm{~A}_{1}^{*}\left(1-\frac{\varepsilon_{\mathrm{y} 0}^{*}}{\varepsilon_{\mathrm{u}}^{*}+\varepsilon_{\mathrm{y} 0}^{*}-\varepsilon_{\mathrm{y}}^{*}}\right)^{\alpha_{1}^{*}}, \varepsilon_{\mathrm{u}}^{*}>\varepsilon_{\mathrm{y}}^{*}\end{cases}
$$

The corresponding constants $\mathrm{A}_{1}{ }^{*}, \alpha_{1}{ }^{*}, \varepsilon_{\mathrm{y} 0}{ }^{*}$ are calculated from experimental data according to abovestated procedure described in Table 1 . Value $\varepsilon_{\mathrm{y}}{ }^{*}$ is calculated by (8). The approximation accuracy is evident from curves 2 in Fig. 1a and b. Dark points are the experiment; the solid line is the calculation.

The universal function of nonlinear creep is assumed as follows:

$$
\begin{aligned}
f_{2}\left(\varepsilon_{u}, T\right) & =\left(1-\omega_{2}\left(\varepsilon_{u}\right)\right)\left(\frac{T_{0}}{T}\right)^{\delta}, \\
\omega_{2}\left(\varepsilon_{u}\right) & = \begin{cases}0, & \varepsilon_{u} \leq \varepsilon_{u} 0 \\
A_{2}\left(1-\frac{\varepsilon_{u}}{\varepsilon_{u}}\right)^{\alpha_{2}}, & \varepsilon_{u}>\varepsilon_{u} 0\end{cases}
\end{aligned}
$$

The creep curves of D-16T alloy at direct Fig. 2a and inverse torsion Fig. 2b of the thin-walled tubes are taken from Namestnikov (1960) study without elastic components. Curve 1 in Fig. 2a corresponds to stress $\sigma_{12}=113.2-\sigma_{12}=127.3-\sigma_{12}=144 \mathrm{MPa}$. Respective curves in Fig. 2 b express double stresses $\sigma_{12}{ }^{*}=2 \sigma_{12}$, $\mathrm{T}=423 \mathrm{~K}$.

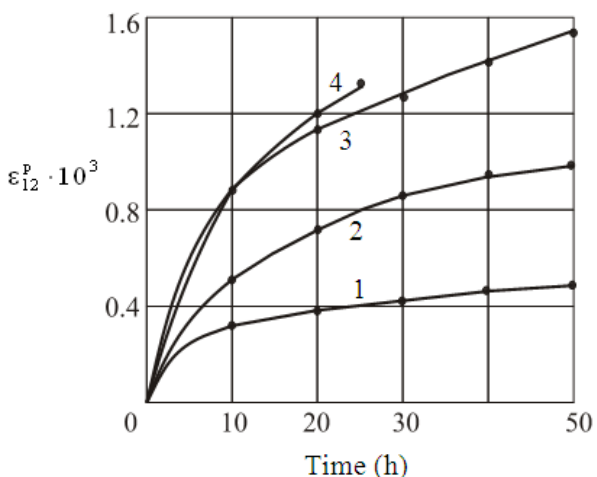

(a)

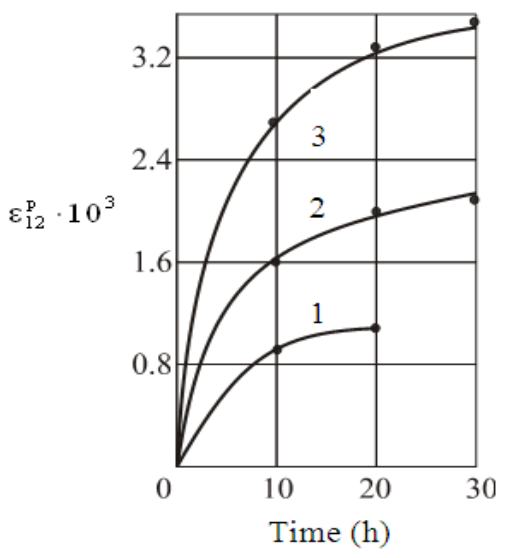

(b)

Fig. 2: The creep curves of D-16T alloy at direct (a) and inverse torsion (b) of the thin-walled tubes are works without elastic components

To calculate temperature constant $\delta$, we used a creep curve for tension: $4-\sigma_{1}=156.8 \mathrm{MPa}, \mathrm{T}=473 \mathrm{~K}$ (Rabotnov, 1979). At back loading the temperature dependence of the process was taken as previously and function $\omega_{2}{ }^{*}\left(\varepsilon_{\mathrm{u}}{ }^{*}\right)$ was accepted similar to (10):

$$
\omega_{2}^{*}\left(\varepsilon_{\mathrm{u}}^{*}\right)= \begin{cases}0, & \varepsilon_{\mathrm{u}}^{*} \leq \varepsilon_{\mathrm{u} 0}^{*} \\ \mathrm{~A}_{2}^{*}\left(1-\frac{\varepsilon_{\mathrm{u} 0}^{*}}{\varepsilon_{\mathrm{u}}^{*}}\right)^{\alpha_{2}^{*}}, \varepsilon_{\mathrm{u}}^{*}>\varepsilon_{\mathrm{u} 0}^{*}\end{cases}
$$

From the experimental data in study by Gusenkov and Moskvitin (1973) follows that deformation in the plastic area at loading from the natural state hardens the material since $\beta_{2}=2.02\left(\varepsilon_{\mathrm{y}}{ }^{*}=\beta_{2} \varepsilon_{\mathrm{y}}\right)$. However, according to Namestnikov (1960) it follows that D-16T alloy weakens as related to creep. As a result of the loading sign change the creep runs faster: $\beta_{2}{ }^{*}=1.98$ $\left(\varepsilon_{\mathrm{u} 0}{ }^{*}=\beta_{2}{ }^{*} \varepsilon_{\mathrm{u} 0}\right)$. 


\section{RESULTS AND DISCUSSION}

After processing of the experimental data using above-described method, we have derived constants $\mathrm{A}_{2}$, $\alpha_{2}, \varepsilon_{\mathrm{u} 0}, \mathrm{~A}_{2}{ }^{*}, \alpha_{2}{ }^{*}, \varepsilon_{\mathrm{u} 0}{ }^{*}$ included in the approximation formulas for the nonlinear creep functions at direct and back loading Table 1. Figure 2 and 3 (curve 1-direct loading, 2-back loading) reflect the conformity of theoretical curves to experimental points.

Rheonomic characteristics of D-16T alloy are described by Rzhanitsyn (1968) kernel of relaxation:

$R(t)=A e^{-\beta t} t^{\alpha-1}(\beta>0,0<\alpha<1)$

This choice is conditioned by simplicity of the kernel, which nevertheless accounts fully enough for the weakly singular properties of materials. The technique of determination of nucleus parameters, corresponding diagrams and tables are given in Koltunov (1976) monograph. Received with their help and according to (11) results are shown on Fig. 4 where the design curve of the function of the pliability is represented on which we can consider the precision of approximation.

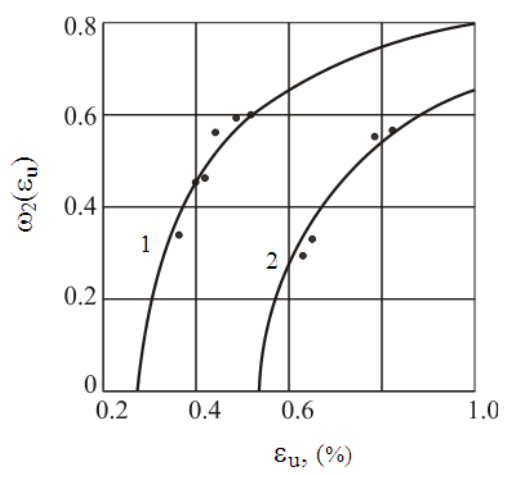

Fig. 3: Conformity between approximation curves of nonlinear creep functions and their experimental points

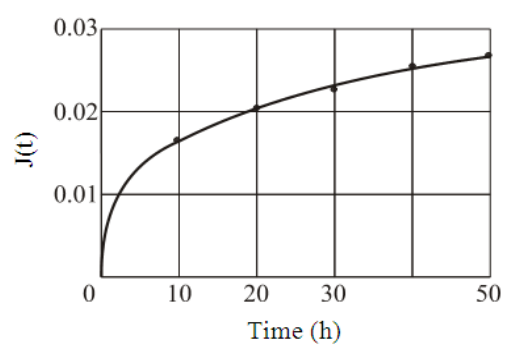

Fig. 4: Conformity of approximation curve of compliance function to its experimental points
Kernel constants along with density $\rho$, specific heat capacity $\mathrm{C}$, specific heat conductivity $\mathrm{k}_{0}$ and ultimate strength $\sigma_{\mathrm{u} 0}$ at normal temperature are given in Table 1 . We should note that all thermo mechanical characteristics of D-16T alloy were received in the field of moderate temperatures ( $\mathrm{T} \leq 543 \mathrm{~K})$.

\section{CONCLUSION}

The methods proposed in the study for experimental curve fitting may be used for other structural materials as well. The approximation results can be employed for numerical solution of the problems in the mechanics of solid bodies.

\section{REFERENCES}

Bell, J.F., 1973. Mechanics of Solids. BerlinHeidelberg, New York, ISBN: 0120020165.

Gorshkov, A.G., E.I. Starovoitov and D.V. Tarlakovskij, 2002. The Theory of Elasticity and Plasticity. FIZMATLIT, Moscow, pp: 416.

Gusenkov, A.P. and G.V. Moskvitin, 1973. Analysis of some approaches to describing cyclic deformation diagrams. Mashinovedenie, 4: 59-67.

Ilyushin, A.A., 1948. Plasticity Elastioplastic Deformations. Gostechizdat, Moscow, pp: 376.

Koltunov, M.A., 1976. Creep and Relaxation. Vysshaya Shkola, Moscow, pp: 277.

Namestnikov, V.S., 1960. Direct and back torsion in creep conditions. J. Applied Mech. Tech. Phys., 1: 121-122.

Rabotnov, Y.N., 1979. Mechanics of a Deformable Solid Body. Nauka, Moscow, pp: 744.

Rzhanitsyn, A.R., 1968. Creep Theory. Stroyizdat, Moscow, pp: 416. 